AB0836

THE INVESTIGATION OF BONE METABOLIC MARKERS ACCORDING TO THE FUNCTIONAL DISORDERS AMONG PATIENTS WITH RHEUMATOID ARTHRITIS

Tetsuya Kawano $^{1}$, Takeshi Kashiwagura ${ }^{2}$, Toshiaki Aizawa ${ }^{3}$, Moto Kobayashi ${ }^{4}$, Masakazu Urayama ${ }^{5}$, Natsuo Konishi ${ }^{6}$, Tsutomu Sakuraba ${ }^{4}$, Hiroki Itoh ${ }^{7}$, Hidekazu Abe ${ }^{8}$, Norio Suzuki ${ }^{9}$, Keiji Kamo $^{10}$, Hiroshi Aonuma ${ }^{5}$, Yusuke Sugimura ${ }^{11}$, Yosuke Iwamoto ${ }^{1}$, Takanori Miura ${ }^{1}$, Naohisa Miyakoshi ${ }^{1}$, Yoichi Shimada ${ }^{1} .{ }^{1}$ Akita University Graduate School of Medicine, Akita, Japan; ${ }^{2}$ Akita City Hospital, Akita, Japan; ${ }^{3}$ Kitaakita Municipal Hospital, Kitaakita, Japan ${ }^{4}$ Hiraka General Hospital, Yokote, Japan; ${ }^{5}$ Ogachi Central Hospital, Yuzawa, Japan; ${ }^{6}$ Akita Kousei Medical Center, Akita, Japan; ${ }^{7}$ Noshiro Kousei Medical Center, Noshiro, Japan; ${ }^{8}$ Ugo Municipal Hospital, Ugo, Japan; ${ }^{9}$ Yuri General Hospital, Yurihonjo, Japan; ${ }^{10}$ Akita Rosai Hospital, Odate, Japan; ${ }^{11}$ Nakadori General Hospital, Akita, Japan

Background: Rheumatoid arthritis (RA) is one of the causes of secondary osteoporosis, and steroids are often used in combination, therefore osteoporosis is highly associated with RA. Furthermore, joint disorders due to RA cause various degrees of dysfunction and ADL declines. The Steinbrocker classification is often used as the degree of dysfunction. Immobilization progresses with the progress of dysfunction, possibly causing severe osteoporosis.

Objectives: Of the 2238 cases in Akita Orthopedic Group omn Rheumatoid Arthrotis (AORA) registry 2017, 101 cases simultaneously measuring bone metabolism markers (TARCP-5b, NTX, urinary DPD, BAP, total P1NP) and pentosidine were involved.

Methods: Patients were divided by Steinbrocker classification into class 1,2 (group A 84 cases) and clss 3, 4 (group B 17 cases). we examined whether there is a difference in bone metabolism markers in each group according to Steinbrocker classification.

Results: The average age in group B (75.9) was significantly higher than group A (66.9) $(p=0.01)$. DAS $28 \mathrm{ESR}$ was significantly higher in group $B(p<0.01)$. There was no difference in eGFR representing renal function between the two groups. The urinary DPD $(\mathrm{nM} / \mathrm{mM} \cdot \mathrm{Cr})$ and pentosidine $(\mu \mathrm{g} / \mathrm{ml})$ in group $B$ was significantly higher than group A $(p$ $<0.01$ ). No difference was observed between the two groups in other bone metabolism markers.

Conclusion: Immobilization by long-term bed rest is known to enhance bone resorption. In 2002, Wakae reported DPD in urine showed a higher value in the group of not going out in femoral neck fracture cases. Based on the results of this study, urinary DPD showed a high value in RA group with high degree of dysfunction, which possibly reflected immobilization due to progress of functional disorder. Moreover, it is known that pentosidine will be higher in cases with high disease activity, severe osteoporosis will be occurred in the group with progressive functional disorder which is difficult to tight control.

Disclosure of Interests: None declared

DOI: 10.1136/annrheumdis-2019-eular.7263

\section{AB0837 INFLUENCE OF AUTO-IMMUNE HEPATOPATHIES ON BONE MINERAL DENSITY}

Hela Kchir ${ }^{1}$, Dhouha Cherif ${ }^{1}$, Dhia Kaffel ${ }^{2}$, Dhilel Issaoui ${ }^{1}$, Maha Mtir ${ }^{1}$, Faten Limaiem ${ }^{3}$, Nadia Maamouri'. ' La Rabta Hospital, Gastroenterology B, Tunis, Tunisia; ${ }^{2}$ Kassab institute, Rheumatology, Tunis, Tunisia; ${ }^{3}$ Mongi Slim Hospital, Pathology, Tunis, Tunisia

Background: Osteoporosis is a common complication of chronic liver diseases especially associated with Primary biliary cholangitis (PBC). Its occurrence during others autoiummune hepatopathies such us autoimmune hepatitis, primary sclerosing cholangitis has been described.

Objectives: The aim of our study was to assess the prevalence of osteoporosis in patients with autoimmune hepatopathies.

Methods: We carried out a retrospective study from January 1996 to December 2018, including all patients with auto-immune hepatopathy [autoimmune hepatitis/Primary biliary cholangitis (PBC)/Primary sclerosing cholangitis (PSC)/overlap syndrome]. Only patients who had bone mineral density (BMD) were selected.

Results: During the study period, 124 patients were included. The mean age of our patients was 55 years [18-87]. BMD has been realised in 51 patient [32 PBC/5AlH/3PSC/11 overlap Syndrome]. It was normal in 18 cases $(35 \%)$, whereas 9 patients had osteopenia (18\%) and 24 had osteoporosis (47\%)[15PBC/2AlH/5overlap/2PSC].

The mean values of L2-L4 T-scores and femur total T-scores were -3.27 and -1.97 , respectively., Osteoporotic patients had an average age of 58 years: 1 men, 3 premenopausal, and 20 postmenopausal women. The study of risk factors of osteoporosis has shown that 5patients underwent systemic corticosteroid. A tobacco intoxication has been noted in 1 patient.
Biochemical analysis indicated a high level of cytolysis (superior to twice normal value) in 14 patient. Cholestasis was noted in 10 patients. The mean values of bilirubin was $23 \mathrm{mg} / \mathrm{l}$. Among the 24 patients with osteoporosis, 10 had positif antinuclear antibodies, 17 had positif anti-mitochondrial antibodies and 5 had positif anti-smooth muscle antibodies. Eight of patients were at an advanced stages of liver fibrosis at the moment of diagnosis.

Conclusion: Our study has shown that autoimmune liver diseases has an influence on bone mineral density as a bone nineral loss was noted in more than half of the cases. It should be considered for all patients with auto immune hepatopathy especially with long duration of corticosteroid treatment.

Disclosure of Interests: None declared

DOI: 10.1136/annrheumdis-2019-eular.8123

\section{AB0838 COMPARISON OF THE CHARACTERISTICS OF THE OSTEOPOROTIC PATIENTS WITH AND WITHOUT RHEUMATOID ARTHRITIS THROUGH RADIOFREQUENCY ECHOGRAPHIC MULTI SPECTROMETRY}

Elena Kirilova ${ }^{1}$, Nikola Kirilov' ${ }^{2}$, Stoyanka Vladeva ${ }^{1} .{ }^{1}$ Trakia university, Stara Zagora, Bulgaria; ${ }^{2}$ Medical University of Sofia, Stara Zagora, Bulgaria

Background: Osteoporosis is a common bone disease characterized by reduction in bone mass accompanied by microarchitectural changes, resulting in brittle bones and in an increased risk of fractures. Rheumatoid arthritis is a well-known risk factor for the development of osteoporosis. With the introduction of radiofrequency echographic multi spectrometry (REMS), easily evaluation of the lumbar spine bone mineral density (BMD) ultrasound (BMDus) and hip BMDus is possible for early diagnosis of osteoporosis.

Objectives: The aim of this study is to compare the characteristics of the osteoporotic patients with and without rheumatoid arthritis through radiofrequency echographic multi spectrometry.

Methods: A total of 70 patients with osteoporosis were included in the study. $43 \%$ of them $(30 / 70)$ had RA and $57 \%$ (40/70) were without RA. Patients were diagnosed with rheumatoid arthritis if they had a score of 6/10 or higher based on 2010 ACR/EULAR classification criteria for RA. Age, body mass index (BMI), lumbar spine BMDus, as well as total hip BMDus and fracture risk score (FRAX) were assessed.

Results: Patients with RA were significantly younger $(69.3 \pm 6.5$ years than those without RA $(76.4 \pm 5.0$ years $)(p=0.002)$. BMl values did not differ significantly between the two groups $\left(25.76 \pm 4.82 \mathrm{~kg} / \mathrm{m}^{2}\right.$ for patients with RA and $27.57 \pm 5.37 \mathrm{~kg} / \mathrm{m}^{2}$ for patients without RA). Patients with and without RA did not show any significantly differences between BMDus values of L1-L4 $\left(0.629 / 0.607 \mathrm{~g} / \mathrm{cm}^{2}\right.$ for L1, $0.692 / 0.688$ $\mathrm{g} / \mathrm{cm}^{2}$ for L2, $0.761 / 0.743 \mathrm{~g} / \mathrm{cm}^{2}$ for $L 3$ and $0.789 / 0.769 \mathrm{~g} / \mathrm{cm}^{2}$ for L4). Patients with RA had higher total lumbar spine T-score $(-2.6 \pm 0.8$ standard deviations) compared to those without RA $(-3.1 \pm 0.5$ standard deviations), but this difference was not significant $(p>0.05)$. Femoral neck BMDus, trochanteric BMDus and total hip BMDus were similar in the groups with and without RA $\left(0.550 / 0.548 \mathrm{~g} / \mathrm{cm}^{2}\right.$ for femoral neck, 0.710 / $0.693 \mathrm{~g} / \mathrm{cm}^{2}$ for trochanter, $0.688 / 0.678 \mathrm{~g} / \mathrm{cm}^{2}$ for total hip). FRAX score of the patients with RA was significantly higher $(32.89 \%$ for 10 -year probability of major osteoporotic fracture and $14.29 \%$ for 10 -year probability of hip fracture) compared to the patients without RA $(22.36 \%$ for 10-year probability of major osteoporotic fracture and $8.75 \%$ 10-year probability of hip fracture).

Conclusion: Although there were no significant differences in lumbar spine BMDus values and total hip BMDus values between the patients with and without RA, patients with RA showed higher 10-year probability of major osteoporotic fracture and hip fracture.

\section{REFERENCES}

[1] Conversano F, Franchini R, Greco A, Soloperto G, Chiriacò F, Casciaro E, Aventaggiato M, Renna MD, Pisani P, Di Paola M, Grimaldi A, Quarta L, Quarta E, Muratore M, Laugier P, Casciaro S (2015) A novel ultrasound methodology for estimating spine mineral density. Ultrasound Med Biol 41:281-300

[2] Casciaro S, Peccarisi M, Pisani P, Franchini R, Greco A, De Marco T, Grimaldi A, Quarta L, Quarta E, Muratore M, Conversano F (2016) An advanced quantitative echosound methodology for femoral neck densitometry. Ultrasound Med Biol 42:1337-1356

[3] Casciaro S, Conversano F, Pisani P, Muratore M (2015) New perspectives in echographic diagnosis of osteoporosis on hip and spine. Clin Cases Miner Bone Metab 12:143-151 
[4] Heidari B, Hassanjani Roushan MR. Rheumatoid arthritis and osteoporosis. Caspian J Intern Med. 2012;3(3):445-6.

[5] Sözen T, Özışık L, Başaran NÇ. An overview and management of osteoporosis. Eur J Rheumatol. 2016;4(1):46-56

Disclosure of Interests: None declared

DOI: 10.1136/annrheumdis-2019-eular.2203

\section{AB0839 ASSOCIATION BETWEEN BODY FAT AND BONE MINERAL DENSITY IN POSTMENOPAUSAL WOMEN THROUGH RADIOFREQUENCY ECHOGRAPHIC MULT SPECTROMETRY}

Elena Kirilova ${ }^{1}$, Nikola Kirilov ${ }^{2}$, Stoyanka Vladeva ${ }^{1} .{ }^{1}$ Trakia university, Stara Zagora, Bulgaria; ${ }^{2}$ Medical University of Sofia, Stara Zagora, Bulgaria

Background: Osteoporosis is characterized by reduced bone mineral density (BMD) and increased fracture risk. Age, concomitant diseases, body mass index (BMI), body composition, etc. are important risk factors that could reflect on bone density and on the increased risk of fractures. Although obesity has been associated with increased bone mineral density (BMD) in the most studies, the relationship between body fat and $\mathrm{BMD}$ remains contradictive.

Objectives: The aim of this study is to determine if there is any association between body fat distribution and bone mineral density in postmenopausal women through novel ultrasound technique applicable on bothlumbar spine and femoral neck.

Methods: A total of 98 women with mean age $62 \pm 11$ years underwent radiofrequency echographic multi spectrometry (REMS). Bioelectrical impedance analysis (BIA) software was used to assess body fat percentage. Patients were divided into two groups-with body fat $>32 \%$ and body fat $<32 \%$. Age, BMI, lumbar spine BMD, total hip BMD and fracture risk score (FRAX) were compared between the patients with normal body fat and those with high body fat.

Results: The mean age of the women with normal body fat was 61.1 \pm 14.6 years and the mean age of the women with high body fat was $63.3 \pm 9.5$ years. BMI of the women with body fat $<32 \%$ was significantly lower $\left(22.5 \mathrm{~kg} / \mathrm{cm}^{2}\right)$ compared to the BMl of the women with body fat $\geq$ $32 \%\left(30.2 \mathrm{~kg} / \mathrm{cm}^{2}\right)(p=0.000)$. Bone mineral density of L1-L4 and tota lumbar spine BMD did not differ between the women with normal body fat and high body fat. Femoral neck BMD, trochanteric BMD and total hip BMD of the patients with normal body fat $\left(0.604 \mathrm{~g} / \mathrm{cm}^{2}, 0.737 \mathrm{~g} / \mathrm{cm}^{2}\right.$ and $0.736 \mathrm{~g} / \mathrm{cm}^{2}$ respectively) were significantly lower than those patients with high body fat $\left(0.682 \mathrm{~g} / \mathrm{cm}^{2}, 0.864 \mathrm{~g} / \mathrm{cm}^{2}\right.$ and $0.838 \mathrm{~g} / \mathrm{cm}^{2}$ respectively) ( $p=0.000$ for femoral neck $B M D$ and trochanteric $B M D$, and $p=$ 0.001 for total hip BMD). FRAX score for 10 -year probability of major osteoporotic fracture did not differ significantly between the two groups (20.8\% for women with normal body fat and $16.6 \%$ for women with high body fat). FRAX score for 10-year probability of hip fracture was also not significant between the two groups, but there was a trend to statistical significance $(p=0.059)$ ( $9 \%$ for women with normal fat and $4.9 \%$ for women with high fat)

Conclusion: Postmenopausal women with body fat $>32 \%$ showed higher femoral neck BMD compared to those with body fat $<32 \%$, but there was no significant difference in the lumbar spine BMD values between the groups. Women with high body fat did not show significantly lower FRAX score than the women with normal body fat.

\section{REFERENCES}

11] Paola Pisani, Francesco Conversano, FernandaChiriacò, Eugenio Quarta, Laura Quarta, MaurizioMuratore, Aimè Lay-Ekuakille, Sergio Casciaro. Estimation of femoral neck bone mineral density by ultrasound scanning: Preliminary results and feasibility. Measurement, Volume 94, 2016, pp. 480-486

[2] Shapses SA, Sukumar D. Bone metabolism in obesity and weight loss. Annu Rev Nutr. 2012;32:287-309.

[3] SILVA, Ana Carolina Veiga, et al. Factors associated with osteopenia and osteoporosis in women undergoing bone mineral density test. Rev. Bras. Reumatol. [online]. 2015, vol.55

[4] Zhao LJ, Jiang H, Papasian CJ, et al. Correlation of obesity and osteoporosis: effect of fat mass on the determination of osteoporosis. $J$ Bone Miner Res. 2007;23(1):17-29.

\section{$\mathrm{AB} 0840$}

SCREENING FOR OSTEOPOROSIS IN AN AMBULATORY AND HOSPITALIZED POPULATION: A 6YEAR EXPERIENCE IN A UNIVERSITY HOSPITAL

Olivier Malaise ${ }^{1}$, Marie Detroz ${ }^{1}$, Mathieu Leroy ${ }^{1}$, Lorenzo Leonori ${ }^{1}$, Laurence Seidel ${ }^{2}$, Michel Malaise ${ }^{1} .{ }^{1}$ Chu De Liège, Department of Rheumatology, Liège, Belgium; ${ }^{2}$ Chu De Liège, Department of Biostatistics, Liège, Belgium

Background: Osteoporosis (OP) is a serious and prevalent disease identified by Dual Energy X-ray Absorptiometry (DEXA) that can be performed in an ambulatory or an hospitalized population.

Objectives: Aims are: (1) to characterize patients who had DEXA in a university department of rheumatology to study its diagnostic efficacy; (2) to look after risk factors specific to our population; (3) to evaluate the efficiency of a non-systematic and opportunistic intra-hospital OP screening by comparing results for ambulatory and hospitalized patients in the different departments of the hospital.

Methods: From 2007 to 2012, 6406 initial DEXA from consecutive patients were prospectively encoded (1494 in 2007, 1158 in 2008, 1079 in 2009, 945 in 2010, 868 in 2011 and 862 in 2012) (identical DEXA). Results: Cohort characteristics are the following: women $74.4 \%$, mean age ( \pm 1 standard deviation) 60.5 years $( \pm 14.3)$, mean BMI 25.1 ( \pm 5.1 , history of corticotherapy in $30.5 \%$, previous fracture in $29 \%$ and current hospitalization in $28.8 \%$ of cases. OP (at one of the 3 sites) was diagnosed in $22.3 \%$, a stable value over the years, with, as a repartition, lumbar spine, femoral neck and total hip OP in $13.7 \%, 13.6 \%$ and $9.2 \%$ respectively. In $3.9 \%$, OP was diagnosed at all the 3 sites. In univariate analysis, OP risk factors were age, history of fracture and low BMI (for all 3 sites), corticotherapy (lumbar spine and femoral neck) and male gender (lumbar spine). In multivariate analysis, regardless of site, age, fracture history, low BMI, and male gender increased the OP risk. Intra-hospital screening identified OP (at any of the 3 sites) in $31.8 \%$ (vs $18.5 \%, \quad \mathrm{p}<0.001$ for ambulatory screening) and $\mathrm{OP}$ at 3 sites simultaneously in $7.9 \%$ (vs $2.3 \%, p<0.0001$ ). This better efficiency was stable and present for each year analyzed. The intra-hospital population tested was older [64.2 years (13.2) vs 59 (13.2), $\mathrm{p}<0.0001$ ], with more men $(35.2 \%$ vs $21.7, \quad p<0.0001)$, more history of fracture $(39 \%$ vs 24 $\mathrm{p}<0.0001)$ and with a slightly higher BMI $[25.4$ (5.8) vs 25.1 (4.8), $\mathrm{p}=0.028$ ], with no difference in corticosteroid use. In addition to T-scores analyzes, Z-scores were also compared and showed similar differences with lower Z-scores in the hospitalized population.

Conclusion:

(1) One in five DEXA identified OP at one of the three sites in the ambulatory population but only one in three in the hospitalized patients. Hospital screening is therefore essential and more efficient than the ambulatory one. Hospital time seems to be an opportunity to fill the gaps in ambulatory screening.

(2) Intra-hospital screening targeted an older and more masculine population with more fracture history, which may explain its better performance, which does not decline over the years. Z-score differences revealed that the efficiency difference was not only due to an older age of the hospitalized population but could be secondary to more internistical co-morbidities or treatment deleterious for bones.

(3) In addition to conventional ones, the male gender is a risk factor for OP recalling the importance of screening for all and not only in the female population (which represents $3 / 4$ of the cohort).

Disclosure of Interests: Olivier Malaise Speakers bureau: Amgen, Marie Detroz: None declared, Mathieu Leroy: None declared, Lorenzo Leonori: None declared, Laurence Seidel: None declared, Michel Malaise: None declared

DOI: 10.1136/annrheumdis-2019-eular.422

\section{$\mathrm{AB} 0841$ PROSPECTIVE STUDY OF BONE METABOLISM AND FRACTURE INCIDENCE IN SPINAL CORD INJURY PATIENTS DURING A PERIOD OF 24 MONTHS}

Isabel Martínez Cordellat ${ }^{1}$, Jose Ivorra Cortés ${ }^{1}$, Fátima Torralba Collados ${ }^{2}$ Carmen Grao Castellote ${ }^{2}$, Cristina Alcañiz Escandell, Inmaculada Chalmeta Verdejo ${ }^{1}$, Marta De la Rubia Navarro ${ }^{1}$, Jorge Juan Fragio-Gil ${ }^{1}$, Roxana Gonzalez Mazario $^{1}$, Luis Gonzalez Puig ${ }^{1}$, Elena Grau García ${ }^{1}$, Rosa Negueroles Albuixech ${ }^{1}$, Jose Eloy Oller Rodríguez ${ }^{1}$, Francisco Miguel Ortiz Sanjuan ${ }^{1}$, Cristobal Pávez Perales ${ }^{1}$, Elvira Vicens Bernabeu ${ }^{1}$, Carmen Nájera Herranz ${ }^{1}$, Inés Cánovas Olmos ${ }^{1}$, Jose Andrés Román Ivorra ${ }^{1}$.

${ }^{1}$ Rheumatology Department. HUP La Fe, Valencia, Spain; ${ }^{2}$ Spinal Cord Injury Unit. HUP La Fe, Valencia, Spain

Background: Spinal Cord Injury (SCl) produces a wide variety of changes in systemic physiology that can lead to several complications, 